the segments surrounded at their bases with a circlet of stiff bristle-like hairs.

This nymph was collected only in North Harford Brook on May 16, 17 and 21. It had disappeared from here by June 23. It was collected from the mud-gathering roots of the vegetation along the edges of the stream in fairly great numbers, and was usually buried so deeply in the mud that it was difficult to discern and capture.

\title{
HYPERASPIS PALUDICOLA SZ.
}

Described from Florida. For many years I have owned a specimen doubtfully named as above, which bore the label "Provincetown, Mass.," without other information. On examining the catch of July 5, 1930, made at Dennis, Mass., I found several specimens of the same thing, and have now come to the conclusion that this is another of the many instances of the occurrence of southern species of beetles in the sand plain area of Massachusetts.

\section{HYPERASPIS DISCONOTATA MULS.}

This beetle was described from "L. Sup.," and one record appears in the N. Y. List from "Cascade. Aug."

I took one specimen by sweeping grass on June 5, 1927, and one on May 31, 1930, probably by sweeping in the same meadow in Sherborn, Mass.

C. A. Frost, Framingham, Mass. 

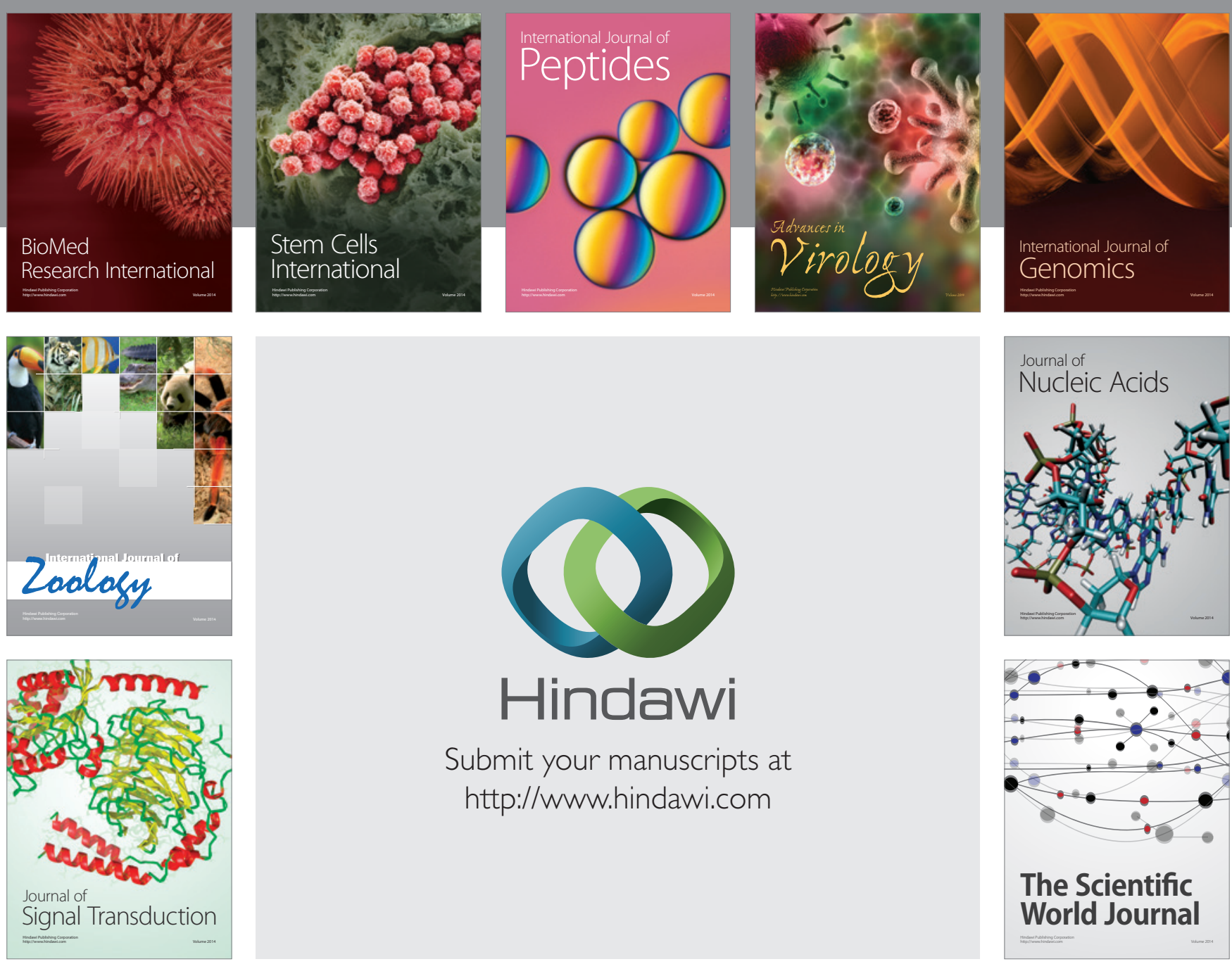

Submit your manuscripts at

http://www.hindawi.com
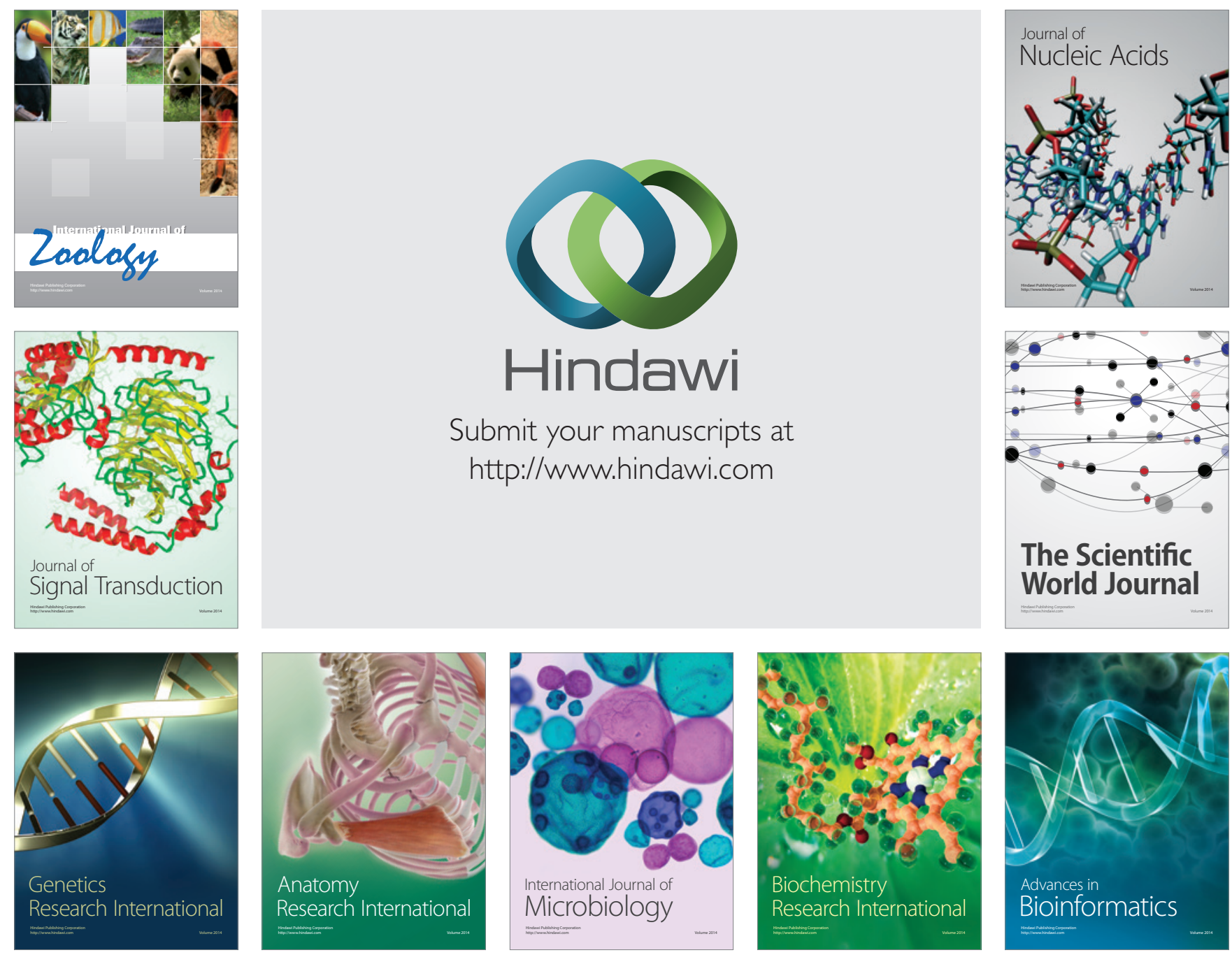

The Scientific World Journal
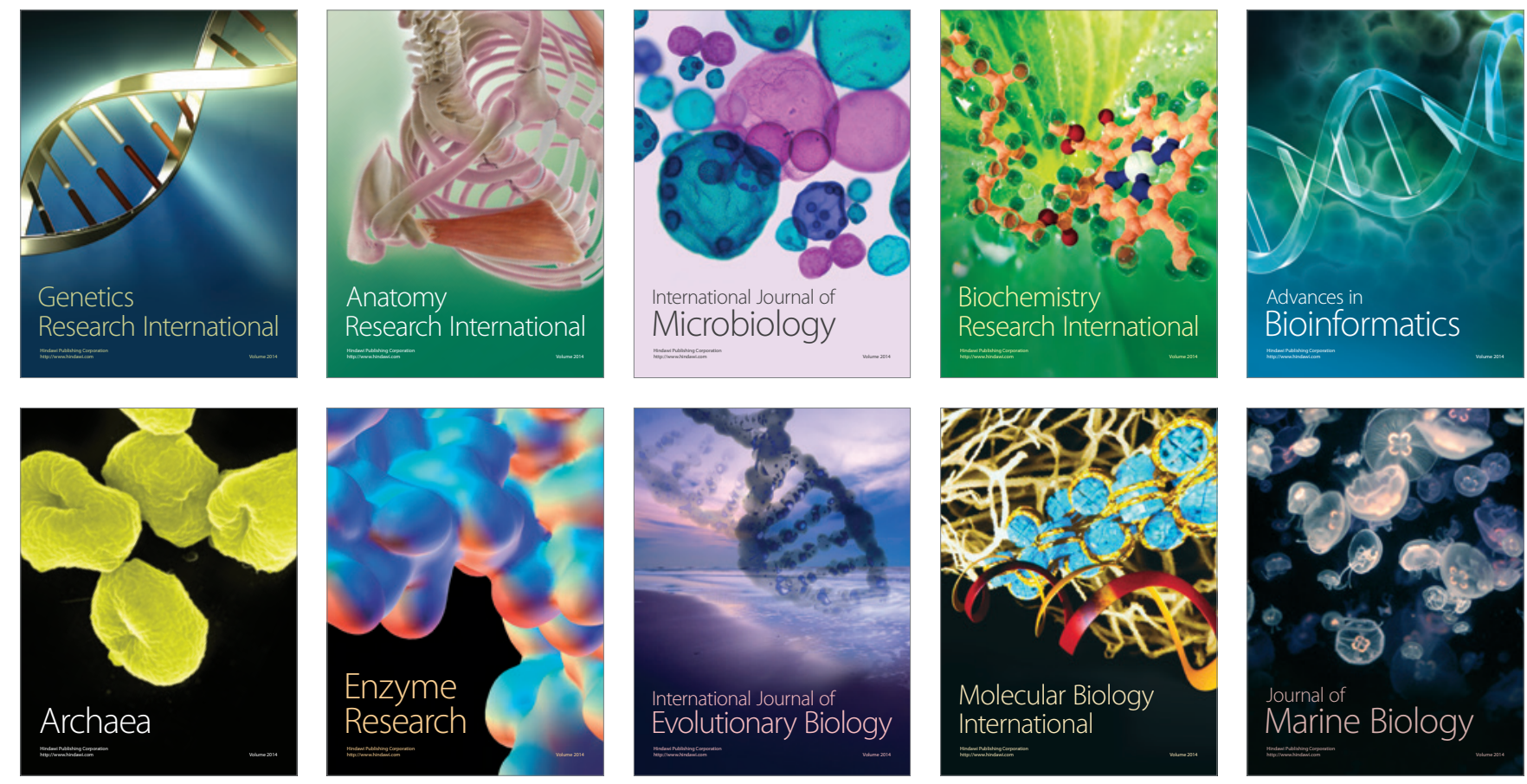